these rogue practitioners continue to abuse the public's trust, often for many years, whilst the GDC is singularly ineffective in responding to concerns raised, even when reported from multiple sources. The inability of the GDC to deal with these cases is a disincentive for registrants to raise concerns and promotes an 'it's somebody else's problem' attitude to prevail. Added to this, DCP registration has produced no discernable benefits for dental staff whilst burdening them with additional expense and taking a significant number of nurses out of the profession who were often part-time and back-up staff. New dental nurses who are often very able but have a weakness in examinations are also cast aside.

Launching its revalidation consultation exercise whilst we are all in the thick of CQC and HTM 01-05 compliance amply demonstrates the lack of insight that the GDC has for the profession and the weight of administration that we have to bear which distracts from our primary concern of patient care.

J. P. Taylor

By email

DOI: 10.1038/sj.bdj.2011.154

\section{TUITION FEE RISE}

Sir, following on from the recent controversy of the Browne Review ${ }^{1}$ and the resultant House of Commons vote to raise the cap on student tuition fees, clinical undergraduate fees will likely rise to $£ 9,000$ per year. Dental or medical graduates will almost certainly be leaving university with a minimum tuition debt of $£ 45,000$.

Should a dental graduate wish to embark on a career within oral and maxillofacial surgery s/he will need to undertake a further clinical degree in medicine. This usually takes the form of an accelerated three or four year course, however, there are still a number of trainees undertaking a full five year programme.

For those on an accelerated course, the NHS bursary system will pay for all but the first year. However, those on a five year course will carry the full cost of tuition fees themselves.

I feel that the recent changes to higher education funding and student finance will result in a career within OMFS being at best, less attractive and at worst, financially elitist. This, alongside the recent discussions regarding the future of oral surgery ${ }^{2}$ may result in fewer dental graduates choosing to undertake a degree in medicine in order to specialise in oral and maxillofacial surgery.

R. Cobb

London

1. Brown J. Securing a sustainable future for higher education. An independent review of higher education funding \& student finance. 12 0ctober 2010. www.independent.gov.uk/browne-report

2. Medical Education England. Oral Surgery Review Group. Dental Programme Board of Medical Education England: Review of Oral Surgery Services and Training. www.mee.nhs.uk/our_work/ work_priorities/review_of_oral_surgery.aspx

DOI: 10.1038/sj.bdj.2011.155

\section{DENOMINATIONS}

Sir, it has been (correctly) brought to my attention that there was an error in the author status and specialty name quoted on my previously published article Oral and maxillofacial surgery - a case of mistaken identity? (BDJ 2011; 210: 9-11).

I am currently a penultimate year dental student - having previously studied medicine and completed my Member of the Royal College of Surgeons (MRCS) examinations. Working part time in oral and maxillofacial surgical jobs during my dental undergraduate training (as a means of gaining both experience and marginally improved financial sustenance) grants me the lengthy denomination 'Part-time Junior Trainee in Oral and Maxillofacial Surgery and simultaneous Penultimate Year Dental Student'.

As (again, correctly) pointed out by our reader, it is only once I have completed my BDS and been successful in obtaining a National Training number, that I may justifiably use the more economical rank of 'Specialist Trainee in Oral and Maxillofacial Surgery'.

Furthermore, concerns were expressed that the opinion provided by the article was perhaps 'inexperienced' and without sufficient referencing. I disagree. The paper primarily portrays the views of those that responded to the questionnaire - which for the majority of cases are Consultants in Oral and Maxillofacial surgery. The lack of references in the paper is primarily due to the fact that it is, as mentioned before, an opinion with no direct reference to previously documented or published word. In fact, the Oxford Dictionary defines opinion as 'a view or judgement formed about something, not necessarily based on fact or knowledge'. ${ }^{1}$

I apologise for any confusion or annoyance caused by the errors in both specialty name and author status. It is not and certainly was not, my intention to deceive or mislead. 'There is no greater mistake than the hasty conclusion that opinions are worthless because they are badly argued.' (Thomas Huxley)

D. van Gijn MBBS BSc MRCS

Dental student

1. Definition of 'opinion'. Oxford Dictionaries. www.oxforddictionaries.com/definition/ opinion?view=uk

DOI: 10.1038/sj.bdj.2011.156

\section{THE OLDEST BRIDGE}

Sir, how long should a bridge last? As a student I was told ten to 15 years, but I have heard that the average NHS bridge in the 1960s lasted less than five. What is the oldest bridge in the UK now? The photo (Fig. 1) illustrates a five unit upper and three unit lower that were placed in 1965 following a machine shop accident. They have been well cared for and the supporting teeth all have good percussion resonances. Sadly I can't remember the name of the laboratory to which most of the credit should go.

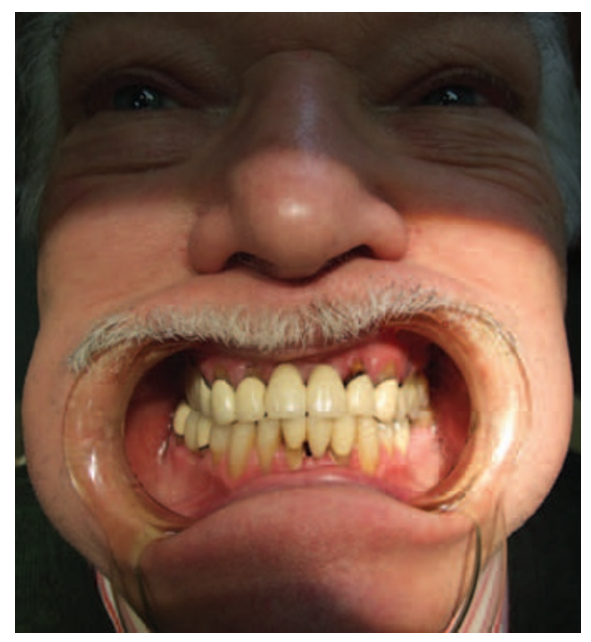

Fig. 1 Five unit upper and three unit lower placed in 1965 